\title{
The association between linagliptin and acute pancreatitis: A review
}

\section{Hyder Osman Mirghani ${ }^{1}$, Abdulmohsen Mohammed Alamri², Muath Fayez Karkar ${ }^{2}$, Muath Saud} Alyasi $^{2}$, Ahmed Abdulrahman Albalawi², Abdullah Ali Aljaafari², Dhafer Mohammed Alyami ${ }^{2}$, and Mohammed Hussain Alzahib²

1. Department of Internal Medicine, Faculty of Medicine, University of Tabuk, Saudi Arabia

2. Medical Intern, Faculty of Medicine, University of Tabuk, Saudi Arabia

\section{REVIEW}

Please cite this paper as: Mirghani HO, Alamri AM, Karkar MF, Alyasi MS, Albalawi AA, Aljaafari AA, Alyami DM, Alzahib $\mathrm{MH}$. The association between linagliptin with acute pancreatitis: A review. AMJ 2019;12(12):344-349. https://doi.org/10.35841/1836-1935.12.12.344-349

\section{Corresponding Author:}

Hyder Osman Mirghani

Department of Internal Medicine, Faculty of Medicine, University of Tabuk, Saudi Arabia

Email: s.hyder63@hotmail.com

\section{ABSTRACT}

\section{Background}

Linagliptin is a Dipeptidyl Peptidase inhibitor (DPP-4i) with rare hypoglycaemic episodes and no need for renal adjustment. However, acute pancreatic is a major concern.

\section{Aims \\ The current review aimed to assess the relationship between linagliptin and acute pancreatitis.}

\section{Methods}

A systematic electronic search was conducted in PubMed, MEDLINE, and the first hundred articles of Google Scholar for relevant articles. All human studies published during the period from 2006 to October 2019 were eligible. Studies on animals, experimental studies, and reviews were excluded. The search terms linagliptin, acute pancreatitis, chronic pancreatitis, and DPP-4i with protean AND or OR were used One hundred and thirty-two articles were retrieved and only six met the inclusion and exclusion criteria. The author's name, country of origin, date of publication, type of study, number of patients, and the duration were reported.

\section{Results}

There were 132 studies (thirty-two in Pub Med and MEDLINE and the first hundred articles in Google Scholar), out of fourteen full texts reviewed, only six studies were eligible. Three were meta-analyses (showed no association of linagliptin with acute pancreatitis, a pooled analysis of 22 randomized controlled trials supported the above observation, while a recent randomized controlled trial concluded acute pancreatitis in 0.3 per cent in linagliptin arm vs. 0.1 per cent placebo of which 2/9 were fatal. The last study was a case report at a high risk of acute pancreatitis due to multiple gallstones and diuretics use.

\section{Conclusion}

Acute pancreatitis was not higher among linagliptin users. Physicians need to take the benefits of this weight and cardiovascular risk-neutral drug with no need for renal adjustment.

\section{Key Words}

Linagliptin, acute pancreatitis, diabetes mellitus

\section{What this review adds:}

\section{What is known about this subject?}

The association between linagliptin and acute pancreatitis is controversial.

\section{What new information is offered in this review?}

There is no causal relationship between linagliptin and acute pancreatitis.

3. What are the implications for research, policy, or practice?

Health care providers need not restrict the use of linagliptin due to its importance especially in frail patients with renal impairment. 


\section{Introduction}

Diabetes mellitus is approaching an epidemic, the available antidiabetic medications have been linked to various side effects including hypoglycaemia, weight gain, and cardiovascular events. The association of DPP-4i and acute pancreatitis is a matter of controversy. ${ }^{1}$ Newer and safer treatment options are continuously being investigated and developed, Dipeptidyl peptidase-4 (DPP-4) inhibitors are examples of such development. Although DPP-4 inhibitors have a neutral effect, they act to potentiate several endogenous peptides that can exert deleterious cardiovascular actions and may augment the ability of GLP-1 to stimulate cyclic adenosine monophosphate in cardiomyocytes, and aggravate cardiac fibrosis. ${ }^{2,3}$

DPP-4-I although shared the same mechanism of action. However, considerable chemical diversity exists amongst members. ${ }^{4}$ So the association between DPP-4i and pancreatitis observed may not be a class effect. We found nine previous reviews focusing on all DPP-4i with mixed results between the uncertainty of the association of DPP-4i and acute pancreatitis, small increased risk, and reports of the association. ${ }^{5-13}$ Given the above and paucity of literature on the association of linagliptin and acute pancreatitis, an update is highly needed. Thus we conducted this review to assess the association of linagliptin with acute pancreatitis.

\section{Methodology}

\section{Eligibility criteria according to PICOS}

Studies were included if they satisfied the following criteria: Randomized controlled trials, meta-analysis, case studies, and cohorts assessing the relationship between linagliptin and acute pancreatitis.

\section{The literature search and articles selection}

A systematic electronic search was conducted in Pub Med, MEDLINE, and the first hundred articles in Google Scholar. Articles published during the period 2006-October 2019 (since the first DPP-4i was introduced) were eligible. No limitations regarding language. Animal and experimental studies and reviews were excluded. The keywords linagliptin, acute pancreatitis, chronic pancreatitis, and DPP4i with the proteans AND or OR were used. Two authors (HM, and ZA independently screened the titles and abstracts for relevant articles. One hundred and thirty-two articles were retrieved and only six met the inclusion and exclusion criteria. The author's name, country of origin, date of publication, type of study, number of patients, and the duration were reported.
The different stages of the review process were shown in the PRISMA chart (Figure 1).

\section{Results}

Of the six full texts included, three were meta-analyses, one pooled analysis, a randomized controlled study, and a case report, three were from Europe, one study was from Australia, one published in the USA, and one in Turkey (61309 included with a duration range between 12 weeks and 4.5 years. The three retrieved meta-analyses showed no association of linagliptin with pancreatitis, the remaining three studies were a pooled analysis that showed no association of linagliptin and pancreatitis, a randomized controlled study in which there was a numerical increase in pancreatitis (0.3 vs. 0.1) compared to placebo, and a case report predisposed to acute pancreatitis due to multiple gallstones and thiazide diuretics Table 1.

\section{Discussion}

In the current review, a meta-analysis of 53 randomized controlled trials including 33881 patients ${ }^{14}$ showed that DPP-4is including linagliptin had no increased risk of acute pancreatitis when compared to other oral hypoglycaemic medications, Lehrke et al. ${ }^{15}$ conducted a pooled analysis of 22 RCTs (7400 patients were including with duration of up to 102 weeks) concluded that acute pancreatitis was $<0.1$ in both linagliptin and placebo. A meta-analysis of one hundred and thirty-four RCTs with study durations for more than twelve weeks ${ }^{16}$ observed that the overall risk of pancreatitis and pancreatic cancer was not different between DPP4i and comparators. In the present review, Sevencan et al. $^{17}$ reported a case of acute pancreatitis among a patient with multiple gallstones taking linagliptin, it is obvious that the patient is already at risk of acute pancreatitis due to multiple gallstones and thiazide diuretic use, even though pancreatitis resolved on holding linagliptin still this may be a natural process in acute pancreatitis. Thus a cause and effect cannot be withdrawn. A large metaanalysis (44 RCTs/13 on DPP-4i, and including 13,036 patients) ${ }^{18}$ raised the uncertainty of DPP-4i use and acute pancreatitis. The most recent RCT was published in the USA, ${ }^{19}$ the trial included 6,979 patients from 27 countries on linagliptin with a duration of 40 months (The CARMELINA Randomized Clinical Trial.), the study concluded that acute pancreatitis is 0.3 per cent in linagliptin arm vs. 0.1 per cent placebo 2/9 were fatal. Chronic pancreatitis was reported in 0.1 per cent each arm. It is important to note that, the study was intended to evaluate the effect of linagliptin on cardiovascular and kidney outcomes in highly selected patients. Furthermore, we don't know if the increased risk of 0.3 per cent is meaningful. Also, the incidence of acute 
pancreatitis varied considerably among ethnicities and geographical locations. ${ }^{20}$ From the above, the three large meta-analyses, one pooled analysis of RCTs, and a recent randomized controlled trial retrieved showed no associations of DPP-4i (including linagliptin) and acute pancreatitis, the case reported in Turkey was at a high risk of acute pancreatitis due to other risk factors.

\section{Conclusion}

There was no causal relationship between linagliptin and acute pancreatitis. Due to the neutral effects of the above drug on weight and cardiovascular outcomes and that no renal adjustment is needed, physicians need not need to limit the use of linagliptin due to the unjustified fear regarding its associations with acute pancreatitis.

\section{References}

1. American Diabetes Association. 9. Pharmacologic approaches to glycemic treatment: standards of medical care in diabetes-2019. Diabetes care 42. Supplement 1 2019:S90-S102.

2. Zghebi SS, Steinke DT, Rutter MK, et al. Comparative risk of major cardiovascular events associated with secondline antidiabetic treatments: a retrospective cohort study using UK primary care data linked to hospitalization and mortality records. Diabetes Obes Metab. 2016;18(9):916-24. doi: 10.1111/dom.12692. Epub 2016 Jun 30.

3. Roumie CL, Greevy RA, Grijalva CG, Hung AM, Liu X, Murff $\mathrm{HJ}$ et al. Association between intensification of metformin treatment with insulin vs sulfonylureas and cardiovascular events and all-cause mortality among patients with diabetes. JAMA. 2014;311(22):2288-96. doi: 10.1001/jama.2014.4312

4. Berger JP, SinhaRoy R, Pocai A, et al. A comparative study of the binding properties, dipeptidyl peptidase-4 (DPP-4) inhibitory activity and glucose-lowering efficacy of the DPP-4 inhibitors alogliptin, linagliptin, saxagliptin, sitagliptin and vildagliptin in mice. Endocrinol Diabetes Metab. 2017;1(1):e00002. doi: 10.1002/edm2.2. eCollection 2018 Jan.

5. Mikhail N. Safety of dipeptidyl peptidase 4 inhibitors for treatment of type 2 diabetes. Curr Drug Saf. 2011;6(5):304-9.

6. Blonde L, Montanya E. Comparison of liraglutide versus other incretin-related anti-hyperglycaemic agents. Diabetes Obes Metab. 2012;14 Suppl 2:20-32. doi: 10.1111/j.1463-1326.2012.01575.x.

7. Scheen A. Gliptins (dipeptidyl peptidase-4 inhibitors) and risk of acute pancreatitis. Expert Opin Drug Saf. 2013;12(4):545-57.
10.1517/14740338.2013.793671. Epub 2013 Apr 27.

8. Filippatos TD, Athyros VG, Elisaf MS. The pharmacokinetic considerations and adverse effects of DPP-4 inhibitors [corrected]. Expert Opin Drug Metab Toxicol. 2014;10(6):787-812. doi: 10.1517/17425255.2014.907274. Epub 2014 Apr 19.

9. Tibaldi JM. Incorporating incretin-based therapies into clinical practice for patients with type 2 diabetes. Adv Ther. 2014;31(3):289-317. doi: 10.1007/s12325-0140100-5. Epub 2014 Feb 15

10. Tella SH, Rendell MS. DPP-4 inhibitors: focus on safety. Expert Opin Drug Saf. 2015;14(1):127-40. doi: 10.1517/14740338.2015.977863. Epub 2014 Dec 9.

11. Giorda CB, Sacerdote C, Nada E, et al. Incretin-based therapies and acute pancreatitis risk: a systematic review and meta-analysis of observational studies. Endocrine. 2015;48(2):461-71. doi: 10.1007/s12020014-0386-8. Epub 2014 Aug 22

12. Lo C, Toyama T, Wang $\mathrm{Y}$, et al. Insulin and glucoselowering agents for treating people with diabetes and chronic kidney disease. Cochrane Database Syst Rev. 2018;9:CD011798. doi: 10.1002/14651858.CD011798.pub2

13. Scheen AJ. The safety of gliptins: updated data in 2018. Expert Opin Drug Saf. 2018;17(4):387-405. doi: 10.1080/14740338.2018.1444027. Epub 2018 Mar 3.

14. Rosenstock J, Perkovic V, Johansen OE, et al. Effect of Linagliptin vs Placebo on major cardiovascular events in adults with type 2 diabetes and high cardiovascular and renal risk: The CARMELINA randomized clinical trial. JAMA. 2019;321(1):69-79. doi: 10.1001/jama.2018.18269.

15. Monami M, Dicembrini I, Martelli D, et al. Safety of dipeptidyl peptidase-4 inhibitors: a meta-analysis of randomized clinical trials. Curr Med Res Opin. 2011;27 Suppl 3:57-64. doi: 10.1185/03007995.2011.602964.

16. Lehrke M, Marx N, Patel S, Seck T, Crowe S, Cheng K et al. Safety and Tolerability of Linagliptin in Patients With Type 2 Diabetes: A Comprehensive Pooled Analysis of 22 Placebo-controlled Studies. Clin Ther. 2014 Aug 1;36(8):1130-46. doi: 10.1016/j.clinthera.2014.06.008. Epub 2014 Jul 8.

17. Monami M, Dicembrini I, Mannucci E. Dipeptidyl peptidase-4 inhibitors and pancreatitis risk: a metaanalysis of randomized clinical trials. Diabetes Obes Metab. 2014;16(1):48-56. doi: 10.1111/dom.12176. Epub 2013 Jul 28.

18. Lo C, Toyama T, Wang Y, et al. Insulin and glucoselowering agents for treating people with diabetes and chronic kidney disease. Cochrane Database Syst Rev. 2018;9:CD011798. 
10.1002/14651858.CD011798.pub2

19. Sevencan NO, Ozkan AE, Kayhan B. Linagliptin-related pancreatitis in a diabetic patient with biliary calculus: A case report. Medicine (Baltimore). 2018;97(50):e13284. doi: 10.1097/MD.0000000000013284.

20. Pendharkar SA, Mathew J, Zhao J, et al. Ethnic and geographic variations in the incidence of pancreatitis and post-pancreatitis diabetes mellitus in New Zealand: a nationwide population-based study. N Z Med J. 2017;130(1450):55-68.

\section{ACKNOWLEDGEMENTS}

The authors would like to acknowledge the Saudi Digital library for accessing the databases

\section{PEER REVIEW}

Not commissioned. Externally peer reviewed.

\section{CONFLICTS OF INTEREST}

The authors declare that they have no competing interests.

\section{FUNDING}

None 
Figure 1: Flow chart throws the different phases of a systematic review (PRISMA flowchart)
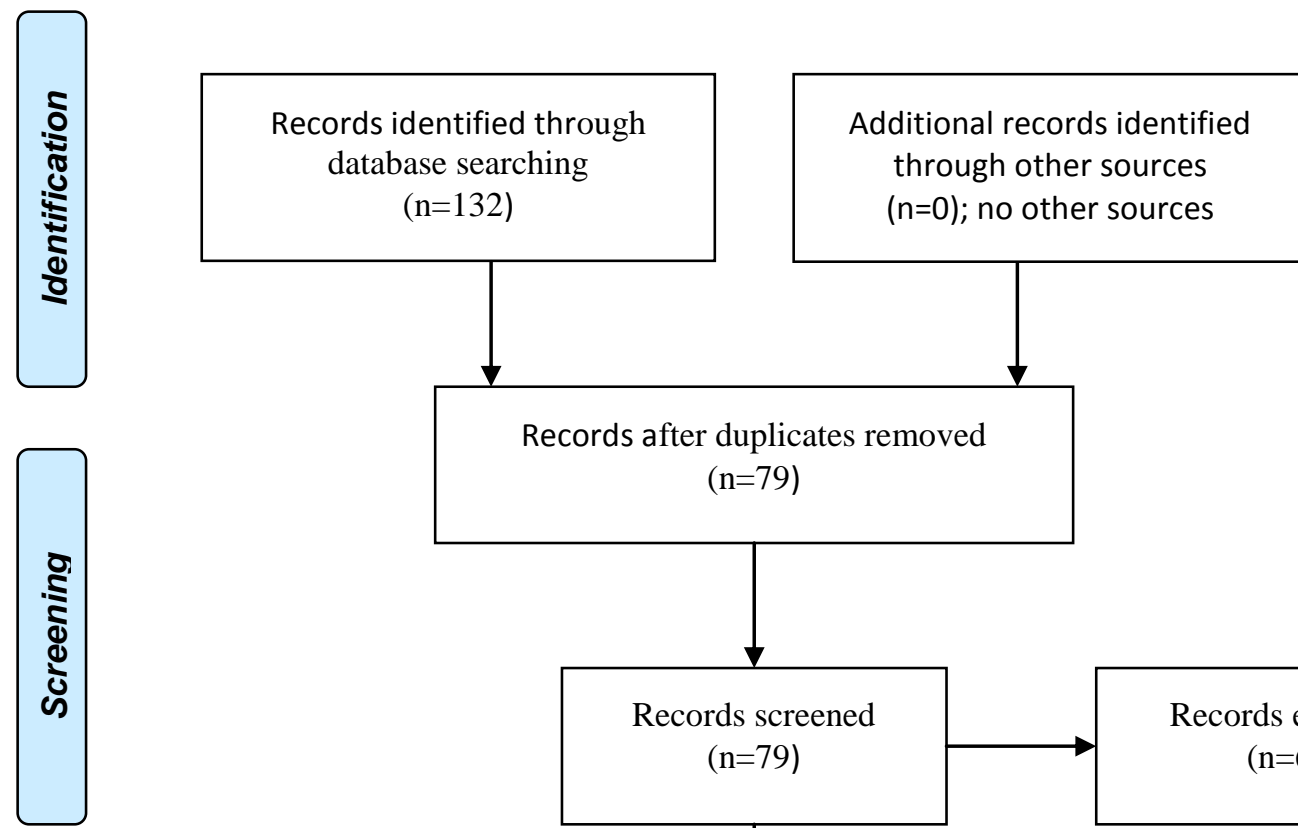

Records after duplicates removed $(n=79)$
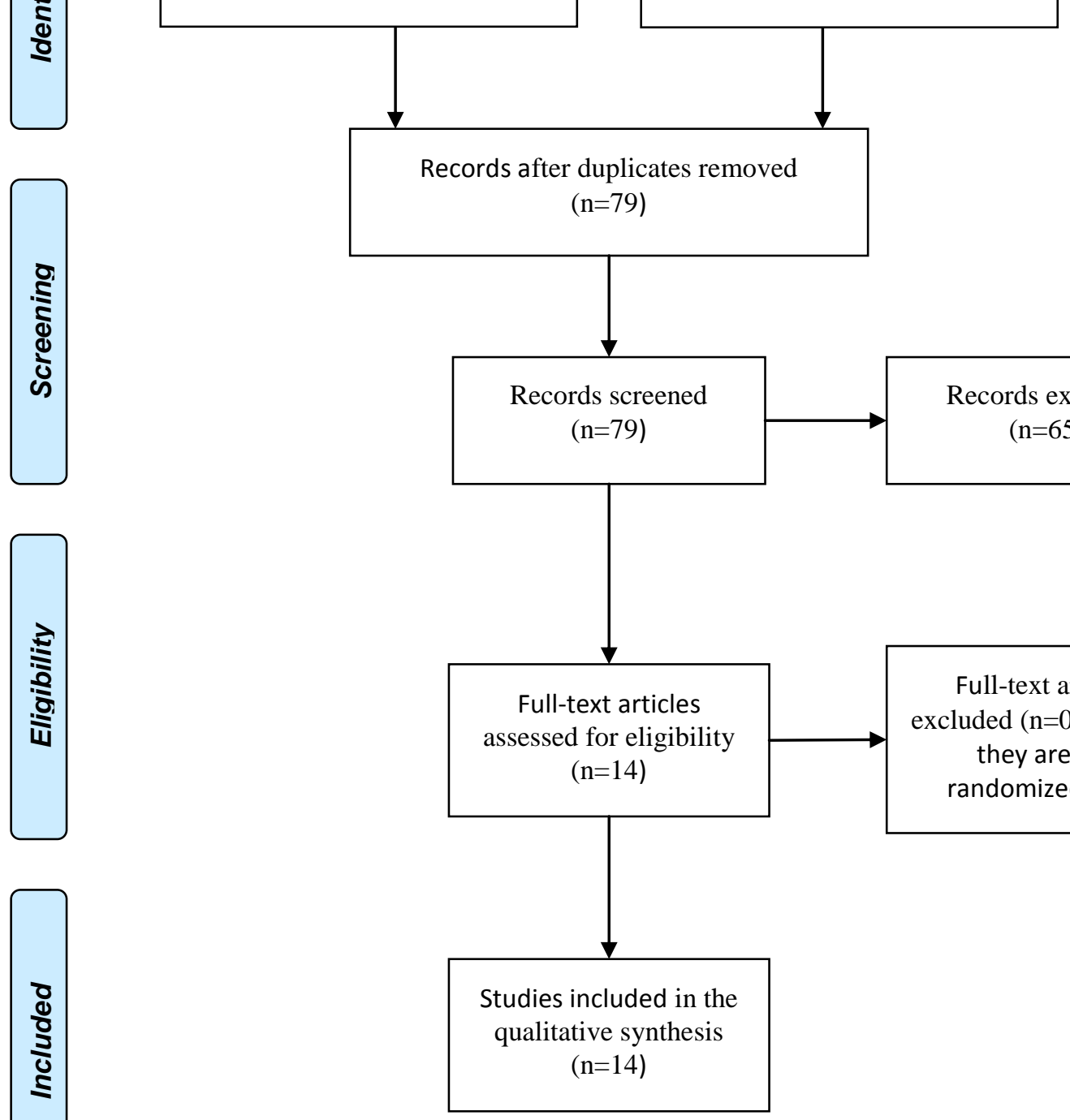

Records excluded $(\mathrm{n}=65)$

Full-text articles excluded $(n=0)$ because they are not randomized trials 
Table 1: The relationship of linagliptin to acute pancreatitis

\begin{tabular}{|c|c|c|c|c|c|c|}
\hline Author & Year & Country & Type & Patients & Duration & Result \\
\hline $\begin{array}{l}\text { Monami et } \\
\text { al. }\end{array}$ & 2011 & Italy & A meta-analysis of 53 RCTs & 33881 & 24 weeks & $\begin{array}{l}\text { DPP-4i had a similar risk } \\
\text { of pancreatitis compared } \\
\text { to other antidiabetic } \\
\text { drugs }\end{array}$ \\
\hline Lehrke et al. & 2014 & Germany & Pooled analysis of 22 RCTs & 7400 & $<102$ weeks & $\begin{array}{l}\text { Acute pancreatitis was } \\
<0.1 \text { in both linagliptin } \\
\text { and placebo }\end{array}$ \\
\hline $\begin{array}{l}\text { Monami et } \\
\text { al. }\end{array}$ & 2014 & Italy & $\begin{array}{l}\text { A meta-analysis of } 134 \\
\text { RCTs }\end{array}$ & & $\geq 12$ weeks & $\begin{array}{l}\text { The overall risk } \\
\text { of pancreatitis and } \\
\text { pancreatic cancer was } \\
\text { not different between } \\
\text { DPP4i and comparators }\end{array}$ \\
\hline $\begin{array}{l}\text { Sevencan et } \\
\text { al. }\end{array}$ & 2018 & Turkey & Case report & & & $\begin{array}{l}\text { Pancreatitis in a patient } \\
\text { with multiple gallstones } \\
\text { on linagliptin }\end{array}$ \\
\hline Lo et al. & 2018 & Australia & $\begin{array}{l}\text { A review and meta- } \\
\text { analysis of } 44 \mathrm{RCT}, 13 \text { on } \\
\text { DPP- } 4 \mathrm{I} \text {, the rest on insulin } \\
\text { and other anti-diabetic } \\
\text { medications }\end{array}$ & 13,036 & & $\begin{array}{l}\text { The association of DPP- } 4 \mathrm{i} \\
\text { and pancreatitis is } \\
\text { uncertain }\end{array}$ \\
\hline $\begin{array}{l}\text { Rosenstock } \\
\text { et al. }\end{array}$ & 2019 & USA & $\mathrm{RCT}$ & 6991 & 4.5 years & $\begin{array}{l}\text { Acute pancreatitis } 0.3 \% \\
\text { in linagliptin arm vs. } 0.1 \% \\
\text { placebo } 2 / 9 \text { were fatal. } \\
\text { Chronic pancreatitis } 0.1 \% \\
\text { each }\end{array}$ \\
\hline
\end{tabular}

